Preface

\section{Hot Topics IV}

\author{
Emmanuel J. Favaloro, PhD, FFSc (RCPA) ${ }^{1}$ \\ ${ }^{1}$ Department of Haematology, Institute of Clinical Pathology and \\ Medical Research (ICPMR), Westmead Hospital, Westmead, Australia \\ Semin Thromb Hemost 2013;39:1-4.
}

Welcome to the first issue of Seminars in Thrombosis $\mathcal{E}$ Hemostasis for 2013, and the fourth issue compilation entitled "Hot Topics." ${ }^{1-3}$ Those previous issues were very popular with our readership, as identified in subsequent analyses. ${ }^{4-6}$ Although Seminars in Thrombosis \& Hemostasis is a themedriven publication, the occasional opportunity will be taken to publish a composite issue of articles of current interest and controversy as the need arises. This opportunity has presented itself as a result of the most recent (2012) Eberhard F. Mammen Young Investigator Awards. ${ }^{6}$ Accordingly, I am very pleased to present the latest "Hot Topics" issue, including articles from five of our Young Award winners. The remaining seven articles derive from various contributors, including several from editorial members of this journal.

The issue begins with a conceptual contribution from Bernard, Armstrong-Wells, and Goldenberg, ${ }^{7}$ the third contributor being one of the Eberhard Mammen award winners. The development of well-designed cohort studies in rare diseases can lead to the discovery of new risk factors and prognostic markers, enhance understanding of natural history and outcomes, and provide preliminary data for randomized controlled trials of treatment strategies. The objective of this manuscript is to discuss the design and implementation of an institution-based prospective inception cohort study, with applied examples in pediatric stroke and thrombosis. Furthermore, the authors discuss the ongoing management and quality assurance mechanisms necessary to optimize such a study. Such an approach can provide critical observational evidence on natural history and prognostic factors, and following multicenter validation, it can inform the design and execution of much-needed randomized controlled clinical trials.

The second article, by Joseph Italiano, another Eberhard Mammen award winner, unravels mechanisms that control platelet production. ${ }^{8}$ Platelets are formed by giant precursor cells (megakaryocytes) that reside within the bone marrow. The generation of platelets, and their release into the blood-

\footnotetext{
Address for correspondence and Issue Theme Hot Topics IV; Guest reprint requests Emmanuel J. Editor, Emmanuel J. Favaloro, PhD, Favaloro, PhD, FFSC (RCPA), FFSC (RCPA).

Department of Haematology,

Institute of Clinical Pathology and

Medical Research (ICPMR),

Westmead Hospital, Westmead,

Australia (e-mail: emmanuel.

favaloro@swahs.health.nsw.gov.

au).
}

stream by megakaryocytes, require a complex series of remodeling events powered by the cytoskeleton to result in the release of many platelets from a single megakaryocyte. Abnormalities in this process can result in thrombocytopenia (low platelet count) and can lead to increased risk of bleeding. This review nicely describes the process of platelet production in considerable detail and also discusses new insights into novel platelet biology.

The third article, by Bradley J. McEwen, another Eberhard Mammen award winner, and his colleagues, is an original article that investigates the effects of omega- 3 polyunsaturated fatty acids (PUFA) on platelet function in both healthy subjects and subjects with cardiovascular disease (CVD). ${ }^{9}$ Hyperactivation and aggregation of platelets play a major role in thrombosis and hemostasis. Light transmission aggregometry and flow cytometric analyses of platelet activation and platelet-leukocyte aggregates were determined at baseline and after 4 weeks of omega- 3 supplementation. In healthy subjects, omega-3 PUFA significantly reduced ADPinduced and adrenaline-induced platelet aggregation, and it also reduced P-selectin expression on platelets and formation of platelet-monocyte aggregates after activation. There were fewer changes in platelet aggregation and activation found in subjects with CVD. These findings therefore support the recommendation that the omega-3 PUFA doses be higher in CVD patients than among healthy subjects.

The fourth article, by Romaric Lacroix, another award winner, and his PhD supervisor, Francoise Dignat-George, discusses the concept of microparticles as new protagonists in pericellular and intravascular proteolysis. ${ }^{10}$ Microparticles are small vesicles resulting from the shedding of cellular membrane during activation or apoptosis processes. Beyond their well-described procoagulant property, accumulating data show that specific endothelial, leukocytes, and tumorderived microparticles bind plasminogen and vectorize plasminogen activators, leading to an efficient plasmin generation and matrix metalloproteinases activation. This review

Copyright $\odot 2013$ by Thieme Medical Publishers, Inc., 333 Seventh Avenue, New York, NY 10001, USA. Tel: +1(212) 584-4662.
DOI http://dx.doi.org/ $10.1055 / \mathrm{s}-0032-1333463$. ISSN 0094-6176. 
focuses on the molecular equipment of microparticle subpopulations, identifies these microparticles as efficient support for plasmin generation, and also highlights the potential consequences of this newly identified function, as relevant to many biological processes such as fibrinolysis, cell survival, matrix remodeling, angiogenesis, and tumor metastasis.

The fifth article, by Vivien M. Y. Chen, the last of our award winners who contributed to this issue, focuses on tissue factor, which in complex with FVIIa initiates blood coagulation. ${ }^{11}$ It was traditionally believed that separation of FVIIa in the circulation from subendothelial tissue factor was the main control preventing spontaneous initiation of thrombosis, and that circulating cells and endothelium did not express tissue factor protein at rest in the healthy individual. However, tissue factor has been detected in healthy human plasma, and animal models of thrombosis indicate that tissue factor in the circulation can contribute to thrombin generation and fibrin formation after an activation event. Circulating tissue factor, and indeed, most of the tissue factor on the cell surface, is now believed to be "encrypted" or coagulation inactive. This article also discusses potential targets for antithrombotic drug development based on the mechanisms involved in activation of, or "de-encrypting," tissue factor.

The sixth article is by Giuseppe Lippi and colleagues discussing novel and emerging therapies related to thrombus-targeted fibrinolysis. ${ }^{12}$ Giuseppe Lippi was one of the 2012 winners in the category of the Most Popular Article for a previous contribution on "Moderate red wine consumption and cardiovascular disease risk: beyond the "French paradox." ${ }^{2,13}$ Thrombolytic therapy by infusion of analogs of tissue plasminogen activator, other recombinant-based plasminogen activators, and streptokinase and urokinase, aims to clear blood clots and restore blood flow in occluded blood vessels. Thrombolytic therapy is thereby frequently used in patients with myocardial infarction, stroke, peripheral arterial disease, and massive pulmonary embolism. This review reports on important technological innovations, such as thrombus-targeted fibrinolysis with biocompatible nanoparticles, which are notably improving the therapeutic armamentarium against thrombotic and occlusive disorders. In addition to more efficacious and durable thrombolytic effects, there is a concomitantly lowering of the risk of systemic bleeding complications that are typically encountered when using the more standard approach of injection of free or soluble plasminogen activators.

The seventh article, by Gobbi and colleagues, is on the role of protein kinase $C$ isoform $\varepsilon$ (PKC $\varepsilon$ ) in hematopoiesis, and raises the question: Does this protein function as a conductor or selector for hematopoietic pathways? ${ }^{14}$ Although mainly known for its cardioprotective properties, PKC $\varepsilon$ is progressively coming of age in terms of its role in hematopoiesis regulation, particularly as related to erythropoiesis, megakaryocytopoiesis, and platelets. PKCE is differentially regulated in erythrocyte and megakaryocyte progenitors, strongly suggesting an addressing role toward maturation of either lineage. This function seems to be played by either selecting progenitors or conducting maturation toward a specific fate. Inappropriate expression of $\mathrm{PKC} \varepsilon$ in human mature platelets may acquire pathophysiological relevance in major thrombotic diseases. Preliminary evidence also suggests that PKC expression may be used as a surrogate marker for thrombotic risk stratification, as well as a possible target for antiplatelet therapy in patients with thrombotic disorders.

The eighth article, by Harenberg and colleagues, discusses novel methods for assessing the oral direct factor Xa and thrombin inhibitors rivaroxaban and dabigatran, and specifically, the use of point-of-care testing of urine samples. ${ }^{15}$ These anticoagulants effectively prevent thromboembolic complications using fixed doses without the need for dose adjustment according to laboratory results. As a significant amount of both drugs are cleared from circulation by glomerular filtration, and thus excreted into urine as active drug, the levels of both agents can be determined in urine. The authors therefore describe a novel point-of-care qualitative assay employing urine to assess drug levels in patients on anticoagulant treatment, and this thus provides an opportunity to easily determine and monitor drug levels using a fairly noninvasive methodology.

The ninth article, by Dentali and colleagues, assesses the relationship between the $\mathrm{ABO}$ blood group and hemorrhage. ${ }^{16}$ Several studies have suggested that patients with non-O blood group have an increased risk of both venous and arterial thromboembolic events. On the contrary, the role of $\mathrm{ABO}$ blood group on the risk of bleeding complications remains unclear. The authors therefore performed a metaanalysis of the literature with the aim of assessing this potential association. This meta-analysis, including a very large sample of bleeding patients and controls, suggests that O blood group is a potentially important genetic risk factor for bleeding. However, high-quality prospective studies are warranted to confirm these preliminary findings.

The tenth article, by Lippi and colleagues, discusses the epidemiology, causes, clinical features, and therapeutic management of massive posttraumatic bleeding. ${ }^{17}$ The pathogenesis of posttraumatic bleeding is complex and multifaceted. The most dramatic phenomenon that always accompanies major hemorrhages is the abrupt and considerable loss of intravascular volume, which further leads to hypovolemic shock, also known as hemorrhagic shock, culminating in peripheral ischemia (especially in those tissues where oxygen delivery is more critical). The mortality rate of severe posttraumatic bleeding can be as high as 50\%, especially when an appropriate treatment is not established in a timely manner. The damage control sequence basically entails a 4-step approach, including damage control surgery, damage control resuscitation with fluid restoration, and hemocomponents administration, as well as correction of the coagulopathy with platelets, antifibrinolytic and/or procoagulant agents such as fresh frozen plasma, prothrombin complex concentrate, or recombinant activated factor VII.

The last two articles are focused on hemostasis-related problems in patients with hematological malignancies. ${ }^{18,19}$ The first of the two, by Franchini and colleagues, discusses bleeding complications, whereas the second, by McMahon and Stein, consider both thrombotic and bleeding complications, although their main focus is on the former. 
Abnormalities of hemostasis are frequently encountered in patients with hematologic malignancies leading to both hemorrhagic and thrombotic adverse events. The prompt recognition and management of such complications, which have a negative impact on the morbidity and mortality of these patients, represent a major challenge for hematologists. The review by Franchini and colleagues describes the most important changes of hemostasis associated with hemorrhage in hematologic malignancies with particular emphasis on their contributory etiologic factors, complex pathogenic mechanisms, clinical manifestations, and therapeutic strategies. ${ }^{18}$ In particular, platelet and acquired coagulation abnormalities, bleeding complications in acute leukemia, and hematopoietic stem cell transplantation are discussed. The review by McMahon and Stein focuses on the Philadelphiachromosome negative myeloproliferative neoplasms (MPN), which share an increased risk of thrombotic and hemorrhagic complications. ${ }^{19}$ Commonly accepted thrombotic risk factors include advanced age, and a prior thrombotic episode, though these risk factors are associated with thrombosis regardless of the presence of an MPN. Emerging risk factors may include leukocytosis and presence of the JAK2 V617F mutation or an increase in its allelic burden. Interventions to prevent and/or treat MPN-related thromboses include aspirin, anticoagulation, and cytoreductive therapy. Hemorrhagic complications occur with extreme thrombocytosis and may be related to acquired platelet defects such as acquired von Willebrand syndrome. The impact of new mutations and novel therapies, including JAK-inhibitors and interferon, on the thrombotic and hemorrhagic tendency remains to be determined.

As always, I thank all the authors of this issue of Seminars in Thrombosis \& Hemostasis for their original and comprehensive contributions. I would especially like to thank the Eberhard F. Mammen Young Investigator Award winners for their submissions. I also hope that the readership of this journal finds this entire issue of considerable interest. This will be determined in time, as measured and established for previous issues of "Hot Topics" compilations. ${ }^{1-6}$

\section{References}

1 Favaloro EJ. Hot Topics I: a potpourri of current issues and controversies in Thrombosis and hemostasis. Semin Thromb Hemost 2007;33(8):723-726
2 Favaloro EJ. Hot topics II: an editorial collection of current issues and controversies in thrombosis and hemostasis. Semin Thromb Hemost 2008;34(1):3-6

3 Favaloro EJ. Hot topics III. Preface. Semin Thromb Hemost 2012; 38(1):1-4

4 Favaloro EJ. Editorial. Winners of the Inaugural Eberhard F. Mammen award for most popular article. Semin Thromb Hemost 2009;35:587-590

5 Favaloro EJ. Winners of the 2010 Eberhard F. Mammen award for most popular article during 2008-2009. Semin Thromb Hemost 2010;36(7):685-692

6 Favaloro EJ. 2012 Eberhard F. Mammen award announcements. Semin Thromb Hemost 2012;38(5):425-432

7 Bernard TJ, Armstrong-Wells J, Goldenberg NA. The institutionbased prospective inception cohort study: design, implementation, and quality assurance in pediatric thrombosis and stroke research. Semin Thromb Hemost 2013;39(1):10-14

8 Italiano J. Unraveling mechanisms that control platelet production. Semin Thromb Hemost 2013;39(1):15-24

9 McEwen BJ, Morel-Kopp M-C, Chen W, Tofler GH, Ward CM. Effects of omega-3 polyunsaturated fatty acids on platelet function in healthy subjects and subjects with cardiovascular disease. Semin Thromb Hemost 2013;39(1):25-32

10 Lacroix R, Dignat-George F. Microparticles: new protagonists in pericellular and intravascular proteolysis. Semin Thromb Hemost 2013;39(1):33-39

11 Chen VMY. Tissue factor de-encryption, thrombus formation, and thiol-disulfide exchange. Semin Thromb Hemost 2013;39(1): 40-47

12 Lippi G, Mattiuzzi C, Favaloro EJ. Novel and emerging therapies: thrombus-targeted fibrinolysis. Semin Thromb Hemost 2013;39 (1):48-58

13 Lippi G, Franchini M, Favaloro EJ, Targher G. Moderate red wine consumption and cardiovascular disease risk: beyond the "French paradox". Semin Thromb Hemost 2010;36(1):59-70

14 Gobbi G, Mirandola P, Carubbi C, Galli D, Vitale M. Protein kinase C $\varepsilon$ in hematopoiesis: conductor or selector? Semin Thromb Hemost 2013;39(1):59-65

15 Harenberg J, Du S, Krämer S, et al. Novel methods for assessing oral direct factor Xa and thrombin inhibitors: use of point-of-care testing and urine samples. Semin Thromb Hemost 2013;39(1):66-71

16 Dentali F, Sironi AP, Ageno W, et al. Relationship between ABO blood group and hemorrhage: a systematic literature review and meta-analysis. Semin Thromb Hemost 2013;39(1):72-82

17 Lippi G, Favaloro EJ, Cervellin G. Massive posttraumatic bleeding: epidemiology, causes, clinical features, and therapeutic management. Semin Thromb Hemost 2013;39(1):83-93

18 Franchini M, Frattini F, Crestani S, Bonfanti C. Bleeding complications in patients with hematological malignancies. Semin Thromb Hemost 2013;39(1):94-100

19 McMahon B, Stein BL. Thrombotic and bleeding complications in classical myeloproliferative neoplasms. Semin Thromb Hemost 2013;39(1):101-111 